\title{
Assessment of efficacy of intravenous fentanyl citrate for attenuation of hemodynamic responses during laryngoscopy and endotracheal intubation
}

\author{
Anuradha Suryaprakash Karande ${ }^{1}$, Sangeeta Shrikant Page," \\ Associate Professor, Dept. of Anaesthesia, Ashwini Rural Medical College Hospital \& Research Centre, Kumbari, Maharashtra, \\ India
}

*Corresponding Author:

Email: sangitapage@gmail.com

Received: $08^{\text {th }}$ September, 2017

Accepted: $13^{\text {th }}$ November, 2017

\begin{abstract}
Introduction: Laryngoscopy and intubation result in stimulation of larynx, pharynx, epipharynx and trachea, which are extensively innervated by autonomic nervous system. The parasympathetic supply is via the vagus and sympathetic supply via superior cervical ganglion. To diminish hemodynamic responses to tracheal intubation, Fentanyl along with hypnotic agents commonly used. Keeping in mind, an attempt has been made to assess the efficacy of injection fentanyl for attenuation of sympathetic response to intubation.

Aims and objective: To assess efficacy of 2 microgram $/ \mathrm{kg}$ body weight fentanyl and 3 microgram $/ \mathrm{kg}$ body weight fentanyl administered before laryngoscopy and endotracheal intubation for attenuation of hemodynamicresponse.

Materials and Methods: 90 normotensive adult patients, belonging to ASA physical status I, of either sex, age group of 18-65 years, free from inter current cardiovascular and neurological disease, were posted for elective surgical procedures under general anaesthesia requiring orotracheal intubation were selected. All were elective cases. Three groups were made. Group I-Control group-10 cc normal saline IV. Group II- 2 microgram $/ \mathrm{kg}$ body weight fentanyl IV diluted to $10 \mathrm{cc}$ with Distillate Water (DW). Group III- 3 microgram/kg body weight fentanyl IV diluted to $10 \mathrm{cc}$ with D.W. Each group comprised of 30 patients.

Result: The rise in pulse rate in both the fentanyl groups, was less and statistically significant than control group ( $\mathrm{p}<0.001$ ). Mild changes in systolic blood pressure were observed in group I and III from baseline. In our study both fentanyl groups II and III showed increase in diastolic blood pressure from baseline. 2 microgram $/ \mathrm{kg}$ and 3 microgram $/ \mathrm{kg}$ IV fentanyl showed less rise in mean arterial pressure, which was statistically significant than control group $(\mathrm{p}<0.001)$.

Conclusion: Use of intravenous fentanyl in both doses, i.e. $2 \mathrm{mcg} / \mathrm{kg}$ as well as $3 \mathrm{mcg} / \mathrm{kg}$ is safe and effective for attenuation of hemodynamic response to laryngoscopy and intubation.
\end{abstract}

Keywords: Fentanyl, Intubation, Laryngoscopy, Hemodynamic.

\section{Introduction}

Since 1940s, Hemodynamic responses tolaryngoscopy and endotracheal intubation has attracted the attention of anesthesiologists. Endotracheal intubation and artificial control of ventilation marked a new era in the history of anesthesia. This had resulted in better control of airway and ventilation making administration of anaesthesia safer. Stimulation of larynx, pharynx, epipharynx and trachea, which are extensively innervated by autonomic nervous system by resultant of Laryngoscopy and intubation. ${ }^{1}$ Stimulation of aforementioned areas results in stimulation of automatic nervous system which in turn leads to various cardiovascular changes, coughing, laryngospasm, bronchospasm, vomiting, pulmonary aspiration, increase in intracranial and intraocular pressures. Hypoxemia and hypercarbia may also occur.

Various methods to reduce these responses have been advocated. These included epinhalational anaesthesia, deep intravenous general anaesthesia, topical anaesthesia with lignocaine, drugs like anti hypertensives, beta adrenoreceptor antagonists (propranolol, metoprolol, esmolol, ${ }^{2}$ labetolol), Gabapentine, $^{3}$ peripheral vasodilators, intravenous lignocaine- lignocaine aerosol ${ }^{4,5}$ Angiotension converting enzyme blockers,Magnesiumsulphate, ${ }^{6}$ alpha2 agonist ( Dexmedetomidine, ${ }^{7}$ Clonidine $^{8}$ ), Droperial, intravenous Ketorolac, Nitroglycerine ointment, Calcium channel blocker, Buprenorphine, Fentanyl $^{9-13}$ and Alfentanil. ${ }^{14-16}$

During laryngoscopy and intubation, fentanyl, $\mu$ receptor agonist is a natural choice to attenuate pressor response. ${ }^{17}$ Low dose fentanyl decreases the circulatory response to tracheal intubation, reduces the dose of thiopentone, has rapid onset of action, extremely lipid soluble, provides cardiovascular stability throughout the operative period, blocks sympathetic stress response to surgical stimulation, rapid and potent analgesic, anxiolytic and sedative and decreases the concentration of inhaled agent requirement. In this study an attempt has been made to assess the efficacy of injection fentanyl for attenuation of sympathetic response to intubation.

\section{Aims and Objectives}

To assess the efficacy of 2 microgram $/ \mathrm{kg}$ body weight fentanyl and $3 \mathrm{microgram} / \mathrm{kg}$ body weight fentanyl administered before laryngoscopy and endotracheal intubation for attenuating the changes in 
the hemodynamic parametersin normotensive individuals.

\section{Materials and Methods}

A total 90 normotensive adult patients belonging to American Society of Anesthesiologists (ASA) physical status I, of either sex between age group of 18-65 years, free from intercurrent cardiovascular and neurological disease undergoing general anaesthesia with orotracheal intubation were selected for study. Institutional ethical committee approval was obtained before beginning of the study. For the conduct of study as well as for administration of general anaesthesia, informed written consentfrom the patients was obtained.

Patients on any drug therapy, menstruating, pregnant and lactating women, pre-existing systematic arterial hypertension, cardiovascular disease, respiratory disease, pre-existing neurological and neuromuscular disorder, anticipated difficulty in mask ventilation or oral endotracheal intubation and patients who required more than 20 seconds for performance of laryngoscopyand intubation were excluded. Under nutrition, anemia, drug dependence, diabetes mellitus, patients not willing to participate in the study were also excluded from the study.

Patients were randomly allocated in three groups, comprising 30 patients in each group.

Group I-Control group-10 cc normal saline IV

Group II- 2 microgram $/ \mathrm{kg}$ body weight fentanyl IV diluted to $10 \mathrm{cc}$ with Distillate Water (DW)

Group III- 3 microgram/kg body weight fentanyl IV diluted to $10 \mathrm{cc}$ with D.W.
All patients were premedicated with intramuscular Glycopyrrolate 4 microgram $/ \mathrm{kg}, 30$ minutes before induction. Mean arterial pressure, pulse rate, systolic blood pressure, diastolic blood pressure, respiratory rate were recorded and continuous ECG monitoring was done. Preoxygenation with $100 \%$ oxygen was carried out for 3 minutes. General anaesthesia was induced with inj. thiopentone sodium $4-5 \mathrm{mg} / \mathrm{kg}$ IV till loss of eyelash reflex. This was followed by Inj. Succinylcholine $1.5-2 \mathrm{mg} / \mathrm{kg}$ IV. Intubation was done after 90 seconds. Direct laryngoscopy and oral endotracheal intubation was performed. Patients in whom intubation took more than one attempt or took more than 20 seconds were excluded from the study. Anaesthesia was maintained with oxygen, nitrous oxide, sevoflurane with controlled ventilation with pancuronium bromideas muscle relaxant. The person making the recordings was kept blind regarding the administered drug. Pulse rate, Systolic Blood Pressure (SBP), Diastolic Blood Pressure (DBP), Mean Arterial Pressure (MAP), Rate Pressure Product (RPP) were recorded before premedication, during laryngoscopy and intubation, 30 seconds, 1 minute, 2 minute and 5 minutes after intubation.

\section{Statistical analysis}

Data were expressed as mean \pm SD. Comparison between two groups was done by student ' $t$ ' test. Comparison between three groups was performed by Analysis of variance test for continuous variables and Chi-square test for categorical variable. A p-value of less than 0.05 was considered significant.

\section{Results}

Table 1: Comparison of mean Pulse Rate (bpm) in three groups

\begin{tabular}{|l|c|c|c|c|}
\hline \multirow{2}{*}{} & \multicolumn{3}{|c|}{ Group } & p-value \\
\cline { 2 - 5 } & I & II & III & \\
\hline $\begin{array}{l}\text { Mean baseline Pulse } \\
\text { rate (per min) }\end{array}$ & $79.4 \pm 5.7$ & $78.7 \pm 5.44$ & $79.06 \pm 5.37$ & 0.89 \\
\hline During laryngoscopy & $101 \pm 5.7$ & $97.86 \pm 7.94 *$ & $96.13 \pm 5.6 * *$ & 0.02 \\
\hline $\begin{array}{l}\text { After Laryngoscopy } \\
\text { and Intubation }\end{array}$ & & & & \\
\hline 30 sec. & $109.96 \pm 5.7$ & $107.4 \pm 4.90^{\mathrm{a}}$ & $96.2 \pm 5.31^{* *}$ & $<0.0001$ \\
\hline 1 min & $110.4 \pm 5.6$ & $99.73 \pm 5.11^{* *}$ & $91.0 \pm 5.37 * *$ & $<0.0001$ \\
\hline 2 min & $110.0 \pm 5.07$ & $99.73 \pm 5.37 * *$ & $89.06 \pm 5.37 * *$ & $<0.0001$ \\
\hline 5 min & $85.0 \pm 5.5$ & $79.3 \pm 5.36^{* *}$ & $71.06 \pm 5.37 * * *$ & $<0.0001$ \\
\hline
\end{tabular}

'a': No significant compared to changes in control group ( $\mathrm{p}>0.05), *$ :Statistically significant compared to control group ( $\mathrm{p}<0.05)$, **: Highly significant compared to control group $(\mathrm{p}<0.001)$

During laryngoscopy at $1 \mathrm{~min}, 2 \mathrm{~min}$ and $5 \mathrm{~min}$ post intubation, increase in pulse rate in group II was less and statistically significant $(\mathrm{p}<0.001)$ compared to group-I. At 30 seconds, changes in group II compared to group I were not significant $(p>0.05)$. As there is maximum sympathetic stimulation at $30 \mathrm{sec}$. postintubation, so low dose of fentanyl i.e. $2 \mu \mathrm{g} / \mathrm{kg}$ is ineffective in attenuation of sympathetic overactivity at 30 seconds. In group I and II, the increase in pulse rate at $30 \mathrm{sec}, 1 \mathrm{~min}$ and $2 \mathrm{~min}$ post intubation were significantly more $(\mathrm{p}<0.001)$ compared to group III. 


\section{Intra group comparison}

Group I /Control group: In the control group i.e. group $\mathrm{I}$, the baseline mean pulse rate was $79.4 \pm 5.7090$. There was a classical pressor response to laryngoscopy and intubation and mean pulse rate showed maximum increase to $110.46 \pm 5.6795$, a rise in pulse by 31.06 (39.12\%) at $1 \mathrm{~min}$. Pulse rate rose significantly above the baseline value during scopy, $30 \mathrm{sec}, 1 \mathrm{~min} .2 \mathrm{~min}$, and $5 \mathrm{~min}$.

Group II: The baseline mean pulse rate was $78.73 \pm$ 5.4452. Mean pulse rate showed maximum increase to $107.4 \pm 4.9032$, a rise in pulse by $28.67(36.41 \%)$ at 30 seconds of laryngoscopy and intubation. Pulse rate rose significantly above the baseline value during scopy, 30 sec, $1 \mathrm{~min}, 2 \mathrm{~min}$ except at $5 \mathrm{~min}$ where the rise was not significant.

Group III: The baseline mean pulse rate was $79.06 \pm$ 5.3751. Mean pulse rate showed maximum increase to $96.2 \pm 5.3136$, a rise in pulse by $17.14(21.68 \%)$ at 30 seconds of laryngoscopy and intubation. Pulse rate rose significantly above the baseline value during scopy, 30 seconds, $1 \mathrm{~min}$ and $2 \mathrm{~min}$. At 5 minute there was significant drop in pulse by $8(10.11 \%)$.

Table 2: Comparison of mean Systolic Blood Pressure (SBP) in three groups

\begin{tabular}{|l|c|c|c|c|}
\hline \multirow{2}{*}{} & \multicolumn{3}{|c|}{ Group } & p-value \\
\cline { 2 - 5 } & I & II & III & \\
\hline $\begin{array}{l}\text { Mean Baseline SBP } \\
\text { (mmHg) }\end{array}$ & $115.6 \pm 8.09$ & $115.73 \pm 7.96$ & $115.86 \pm 7.96$ & 0.99 \\
\hline During laryngoscopy & $127.93 \pm 8.11$ & $123.87 \pm 7.08 *$ & $121.86 \pm 7.96 * *$ & 0.01 \\
\hline $\begin{array}{l}\text { After Laryngoscopy } \\
\text { and Intubation }\end{array}$ & & & & \\
\hline $30 \mathrm{sec}$ & $145.6 \pm 8.31$ & $139.6 \pm 7.86 * *$ & $125.4 \pm 7.98 * *$ & $<0.0001$ \\
\hline $1 \mathrm{~min}$ & $157.6 \pm 8.21$ & $134.73 \pm 7.94 * *$ & $117.86 \pm 7.96 * *$ & $<0.0001$ \\
\hline $2 \mathrm{~min}$ & $147.53 \pm 8.29$ & $133.6 \pm 9.01 * *$ & $107.86 \pm 7.96 * *$ & $<0.0001$ \\
\hline $5 \mathrm{~min}$ & $110.73 \pm 7.96$ & $111.53 \pm 8.43^{* *}$ & $105.9 \pm 7.91 *$ & 0.01 \\
\hline
\end{tabular}

During laryngoscopy, $30 \mathrm{sec}, 1 \mathrm{~min} ., 2 \mathrm{~min}$ post intubation, increase in SBP of group-II was significantly less $(\mathrm{p}<0.001)$ compared to group-I. Fall in SBP at $5 \mathrm{~min}$, in group II was insignificant $(\mathrm{p}>0.05)$ compared to group I. After $30 \mathrm{sec}$ and $1 \mathrm{~min}$, post intubation, the increase in SBP of group III was significantly less $(\mathrm{p}<0.001)$ compared to group-I. At 2 min and 5 min, fall in SBP of group III was significant more $(\mathrm{p}<0.05)$ compared to group I.

\section{Intra group comparison}

Group I /Control group: The mean baseline systolic blood pressure was $115.6 \pm 8.0925$. After laryngoscopy and intubation, there was a classical pressor response and mean SBP showed maximum increase to $157.6 \pm$ 8.2110 , a rise by $42(36.33 \%)$ at $1 \mathrm{~min}$. Mean systolic blood pressure rose significantly above the baseline value during scopy, $30 \mathrm{sec}, 1 \mathrm{~min} .2 \mathrm{~min}$ post intubation. At $5 \mathrm{~min}$. of post intubation there was significant fall in systolic blood pressure by 4.87 $(4.21 \%)$.

Group II: The mean baseline systolic blood pressure was 115.73 \pm 7.9608. Due to laryngoscopy and intubation, mean systolic blood pressure showed maximum increase to $139.6 \pm 7.8623$, a rise by 23.87 $(20.62 \%)$ at 30 seconds. Rise in mean systolic blood pressure was significantly above the baseline value through the study except $5 \mathrm{~min}$. At $5 \mathrm{~min}$., there was significant fall in systolic blood pressure by 4.2 $(3.63 \%)$.

Group III: The baseline mean systolic blood pressure was $115.86 \pm 7.9642$. Mean systolic blood pressure showed maximum increase to $125.4 \pm 7.9853$, a rise by $9.54(8.23 \%)$ at 30 seconds. Rise in mean systolic blood pressure was significant above the baseline value during scopy, 30 seconds. Rise was not significant at 1 min. There was significant fall in mean systolic blood pressure at $2 \mathrm{~min}$. and $5 \mathrm{~min}$. by $8(6.9 \%)$ and by 9.96 $(8.6 \%)$ respectively.

Table 3: Comparison of Diastolic Blood Pressure (DBP) in three groups

\begin{tabular}{|c|c|c|c|c|}
\hline & \multicolumn{3}{|c|}{ Group } & \multirow[b]{2}{*}{ p-value } \\
\hline & I & II & III & \\
\hline $\begin{array}{lll}\begin{array}{l}\text { Mean } \\
(\mathrm{mmHg})\end{array} & \text { Baseline } & \text { DBP }\end{array}$ & $73.73 \pm 3.63$ & $74.06 \pm 3.73$ & $74.66 \pm 3.79$ & 0.62 \\
\hline During laryngoscopy & $91.67 \pm 3.75$ & $86.06 \pm 4.21 *$ & $74.53 \pm 3.78^{* *}$ & $<0.0001$ \\
\hline $\begin{array}{l}\text { After Laryngoscopy and } \\
\text { Intubation }\end{array}$ & & & & \\
\hline $30 \mathrm{sec}$ & $112.06 \pm 4.21$ & $101.46 \pm 3.96 * *$ & $76.8 \pm 4.06 * *$ & $<0.0001$ \\
\hline $1 \mathrm{~min}$ & $113.6 \pm 3.76$ & $95.66 \pm 4.17 * *$ & $76.6 \pm 3.79 * *$ & $<0.0001$ \\
\hline $2 \mathrm{~min}$ & $105.73 \pm 3.78$ & $94.73 \pm 3.95 * *$ & $74.6 \pm 3.79 * *$ & $<0.0001$ \\
\hline $5 \mathrm{~min}$ & $73.8 \pm 3.87$ & $73.26 \pm 4.02^{\mathrm{a}}$ & $73.8 \pm 4.05^{\mathrm{a}}$ & 0.85 \\
\hline
\end{tabular}


After $30 \mathrm{sec}, 1 \mathrm{~min}$ and $2 \mathrm{~min}$ post intubation increase in mean DBP of group II were less $(\mathrm{p}<0.001)$ than group-I and statistically significant. And at $5 \mathrm{~min}$, fall in DBP of group II was insignificant $(\mathrm{p}>0.05)$ compared to group I. The rise in mean DBP from baseline at $30 \mathrm{sec}$ and $1 \mathrm{~min}$ in group III was significantly less $(\mathrm{p}<0.001)$ compared to group I. During scopy, at $2 \mathrm{~min}$, in group III, there was significant fall in mean DBP from baseline, while in group I there was significant rise at $2 \mathrm{~min}$. At $5 \mathrm{~min}$, fall in mean DBP of group III was not significant compared to group-I.

\section{Intra group comparison}

Group I /Control group: The mean baseline diastolic blood pressure was $73.73 \pm 3.6287$. Due to laryngoscopy and intubation, there was a classical pressor response and mean DBP showed maximum increase to $113.6 \pm 3.7655$, a rise by $39.87(54.07 \%)$ at 1 min. Mean diastolic blood pressure rose significantly above the baseline value during scopy, $30 \mathrm{sec}, 1 \mathrm{~min} .2$ min post intubation. At $5 \mathrm{~min}$., there was insignificant rise in systolic blood pressure ( $p>0.05)$.

Group II: The mean baseline diastolic blood pressure was 74.06士 3.7318. Due to laryngoscopy and intubation, mean diastolic blood pressure showed maximum increase to $101.46 \pm 3.9630$, a rise by 27.4 $(37 \%)$ at 30 seconds. There was significant rise in mean diastolic blood pressure above the baseline during scopy, $30 \mathrm{sec}, 1 \mathrm{~min}$, and $2 \mathrm{~min}$. Fall in mean diastolic blood pressure below the baseline by $0.8(1.08 \%)$ at 5 min was insignificant.

Group III: The mean baseline diastolic blood pressure was 74.66 \pm 3.7995. Mean diastolic blood pressure showed maximum increase to $76.8 \pm 4.0576$, a rise by $2.14(2.87 \%)$ at 30 seconds. During laryngoscopy and intubation, there was insignificant fall in mean diastolic blood pressure by $0.13(0.17 \%)$. At $1 \mathrm{~min}$ insignificant rise in mean diastolic systolic pressure above the baseline by $1.94(2.6 \%)$, means there was maximum attenuation and insignificant fall in mean diastolic blood pressure at $2 \mathrm{~min}$. and $5 \mathrm{~min}$.

Table 4: Comparison of Mean Arterial Pressure (MAP) in three groups

\begin{tabular}{|l|c|c|c|c|}
\hline & \multicolumn{3}{|c|}{ Group } & p-value \\
\cline { 2 - 5 } & I & II & III & \\
\hline Mean Baseline MAP & $87.65 \pm 4.50$ & $87.92 \pm 4.39$ & $88.36 \pm 4.71$ & 0.83 \\
\hline During laryngoscopy & $103.73 \pm 4.46$ & $98.67 \pm 4.37 * *$ & $90.26 \pm 4.63 * *$ & $<0.0001$ \\
\hline $\begin{array}{l}\text { After Laryngoscopy } \\
\text { and Intubation }\end{array}$ & & & & \\
\hline $30 \mathrm{sec}$ & $123.21 \pm 4.68$ & $114.17 \pm 4.50 * *$ & $93.02 \pm 4.85 * *$ & $<0.0001$ \\
\hline $1 \mathrm{~min}$ & $128.23 \pm 4.52$ & $108.65 \pm 4.62 * *$ & $90.36 \pm 4.71^{* *}$ & $<0.0001$ \\
\hline $2 \mathrm{~min}$ & $119.63 \pm 4.70$ & $107.58 \pm 4.67 * *$ & $85.7 \pm 4.70^{* *}$ & $<0.0001$ \\
\hline $5 \mathrm{~min}$ & $86.07 \pm 4.63$ & $85.98 \pm 4.59^{\mathrm{a}}$ & $84.44 \pm 4.81^{\mathrm{a}}$ & 0.32 \\
\hline
\end{tabular}

During scopy, $30 \mathrm{sec}, 1 \mathrm{~min}$ and $2 \mathrm{~min}$ post intubation, rise in mean MAP in group II was significantly less $(p<0.0001)$ compared to group I. At 5 min., fall in MAP of group II was not significant ( $>0.05$ ) compared to group I. During scopy, at $30 \mathrm{sec}$ and $1 \mathrm{~min}$, the rise in MAP above baseline in group III was significantly less $(\mathrm{p}<0.001)$ compared to group-I. At 2 min., there was significant fall in MAP of group III, while in group-I there was significant rise. Whereas at 5 min fall was statistically not significant in group III as compared to group I.

\section{Intra group comparison}

Group I /Control group: The mean baseline mean arterial pressure was 87.65 \pm 4.5024. After laryngoscopy and intubation, the mean arterial pressure showed maximum increase to $128.23 \pm 4.5225$, a rise by $40.58(46.30 \%)$ at $1 \mathrm{~min}$. Mean MAP rose significantly above the baseline value during scopy, 30 sec, 1 min. 2 min. At 5 min., there was fall in mean MAP by 1.58 (1.8\%) which was insignificant ( $p>0.05)$. Group II: The mean baseline mean arterial pressure was 87.92 \pm 4.3914. Mean arterial pressure showed maximum increase to $114.17 \pm 4.5058$, a rise by 26.25 $(29.85 \%)$ at 30 seconds. Mean MAP rose significantly above the baseline during scopy, $30 \mathrm{sec}, 1 \mathrm{~min}$, and 2 min. At $5 \mathrm{~min}$ there was fall in mean MAP by 1.94 $(2.21 \%)$ which was insignificant.

Group III: The mean baseline mean arterial pressure was $88.36 \pm 4.7155$. Mean arterial pressure showed maximum increase to $93.02 \pm 4.8516$, a rise by 4.66 $(5.27 \%)$ at 30 seconds. Mean MAP rose significantly above the baseline at $30 \mathrm{sec}$. Rise was not significant during scopy and at $1 \mathrm{~min}$ of post intubation. There was significant fall in mean arterial pressure at $2 \mathrm{~min}$ and 5 min by $2.66(3.01 \%)$ and $3.92(4.44 \%)$ respectively. 
Table 5: Comparison of Mean Rate Pressure Product (RPP) in three groups

\begin{tabular}{|l|c|c|c|c|}
\hline \multirow{2}{*}{} & Group & I & III & p-value \\
\cline { 2 - 5 } & $9174 \pm 894.32$ & $9109.7 \pm 888.46$ & $9148 \pm 748.24$ & 0.83 \\
\hline Mean Baseline RPP & $12910.26 \pm 85.08$ & $12132.4 \pm 994.12^{* *}$ & $11702.53 \pm 877.27^{* *}$ & $<0.0001$ \\
\hline $\begin{array}{l}\text { During } \\
\text { laryngoscopy }\end{array}$ & & & \\
\hline $\begin{array}{l}\text { After Laryngoscopy } \\
\text { and Intubation }\end{array}$ & & & & \\
\hline 30 sec & $15932.26 \pm 1167.08$ & $15001.73 \pm 1125.15 * *$ & $12057.73 \pm 861.22^{* *}$ & $<0.0001$ \\
\hline 1 min & $17407.06 \pm 1257.25$ & $13431.33 \pm 996.40^{* *}$ & $10720.53 \pm 812.70^{* *}$ & $<0.0001$ \\
\hline 2 min & $16231.73 \pm 1163.92$ & $13326.8 \pm 1201.74^{* *}$ & $9594.13 \pm 775.32^{* *}$ & $<0.0001$ \\
\hline 5 min & $9415.73 \pm 887.41$ & $8844.8 \pm 883.76^{*}$ & $7510.4 \pm 679.86^{* *}$ & 0.32 \\
\hline
\end{tabular}

During scopy, $30 \mathrm{sec}, 1 \mathrm{~min}$ and 2 min post intubation, rise in mean RPP in group II was significantly less $(\mathrm{p}<0.0001)$ compared to group I. At 5 min., fall in RPP of group II by 264.93 (2.91\%) which was not significant $(p>0.05)$ compared to group I. During scopy, at $30 \mathrm{sec}, 1 \mathrm{~min}$, and $2 \mathrm{~min}$, the rise in RPP in group III was significantly less $(\mathrm{p}<0.001)$ compared to group-I. At 5 min., there was significant fall shown in RPP of group III, while in group-I there was insignificant rise in RPP.

\section{Intra group comparison}

Group I /Control group: The mean baseline rate pressure product was $9174 \pm 894.3227$. The rate pressure product showed maximum increase to $17407.06 \pm 1257.253$, a rise by $8233.06(89.74 \%)$ at 1 min. Mean rate pressure product rose significantly above the baseline value during scopy, $30 \mathrm{sec}, 1 \mathrm{~min} .2$ min. post intubation. Rise was not significant at $5 \mathrm{~min}$ $(2.63 \%)$.

Group II: The mean baseline rate pressure product was $9109.73 \pm 888.4631$. The mean rate pressure product showed maximum increase to $15001.73 \pm 1125.153$, a rise by $5892(64.68 \%)$ at 30 seconds. The mean rate pressure product rose significantly above the baseline during scopy, $30 \mathrm{sec}, 1 \mathrm{~min}$, and $2 \mathrm{~min}$ post intubation. There was fall in mean rate pressure product at $5 \mathrm{~min}$. by $264.93(2.91 \%)$ which was not significant.

Group III: The mean baseline rate pressure product was 9148 \pm 748.2415. The mean rate pressure product showed maximum increase to $12057.73 \pm 861.2239$, a rise by $2909.73(31.81 \%)$ at 30 seconds. Mean rate pressure product rose significantly above the baseline during scopy, $30 \mathrm{sec}$., $1 \mathrm{~min}, 2 \mathrm{~min}$. At $5 \mathrm{~min}$, there was not significant fall in rate pressure product by 1637.6 $(17.90 \%)$.

\section{Adverse Events observed during study:}

1. None of the 90 patients (of all the groups) had significant hypotension (ie. 30\% fall of SBP from the baseline preoperative value).

2. No serious bradycardia or other rhythm disturbances, truncal rigidity or recall of the laryngoscopy and intubation were noted in any patients (of all the groups).

3. No respiratory depression had been observed in any fentanyl treated patients.

\section{Discussion}

It is understood that, fentanyl suppresses the hemodynamic response during laryngoscopy and intubation by increasing the depth of anesthesia and by decreasing sympathetic discharge. ${ }^{18}$

Pulse Rate: U.M Kautto et al, ${ }^{9}$ studied effect of fentanyl in two different doses ie 2 microgram $/ \mathrm{kg}$ and 6 microgram $/ \mathrm{kg}$ showed that, a significant increase $(p<0.001)$ in pulse rate was observed only in control group. We found similar results with inj. fentanyl $2 \mathrm{microgram} / \mathrm{kg}$ and 3 microgram $/ \mathrm{kg}$ IV in significant attenuation of increase in pulse rate during laryngoscopy. In another study, it was observed that, in hypertensive patients, hemodynamic responses to intubation were controlled effectively in the fentanyl 2 $\mathrm{mcg} / \mathrm{kg}$ groups as well. ${ }^{19}$

Chung and Evans ${ }^{10}$ study showed that no significant increase in heart rate above base line at any level in study group while in control group rise in heart rate was significantly above the baseline at 1 and $2 \mathrm{~min}$ post intubation. Similar results found in our study that pulse rate rose significantly above the baseline at each instance from laryngoscopy, in all three groups but in both fentanyl groups, the increase in pulse rate was statistically significantly less $(\mathrm{p}<0.001)$ as compared to control group.

V. Abraham and B. Kaur, ${ }^{17}$ studied effect of3 microgram $/ \mathrm{kg}$ fentanyl IV, used adjunct to thiopentone, on the circulatory response to tracheal intubation and showed that statistically significant reduction in post intubation tachycardia. The pulse rate showed mild change from baseline. When compared between the groups, this was not significant throughout the study period ( $p>0.05)$. In study group, increase in mean pulse rate during scopy by $17.6(19.90 \%)$, at $1 \mathrm{~min}$ by 12.25 $(13.85 \%)$, at $2 \mathrm{~min}$ by $11.85(13.40 \%)$. These results were similar to results obtained by us. In our study, there was rise in pulse rate during scopy by 
$17.07(21.59 \%)$, at $1 \mathrm{~min}$ by $12(15.18 \%)$, at $2 \mathrm{~min}$ by $10(12.65 \%)$.

Systolic blood presure: U.M. Kautto ${ }^{9}$ study showed that SBP in F6 group did not rise above control level. In control group $(\mathrm{p}<0.001)$ and $\mathrm{F} 2$ group $(\mathrm{p}<0.02)$, SBP increased significantly after intubation compared with baseline values, but the elevation in F2 group was significantly less than the control group $(\mathrm{p}<0.05)$. In our study also, 2microgram $/ \mathrm{kg}$ fentanyl showed less increase in mean SBP $(\mathrm{p}<0.001)$ during scopy at $30 \mathrm{sec}$, $1 \mathrm{~min}, 2 \mathrm{~min}$ post intubation compared to control group. Fentanyl 3 microgram $/ \mathrm{kg}$ IV showed similar changes except at $2 \mathrm{~min}$. At $5 \mathrm{~min}$ with fentanyl $2 \mathrm{microgram} / \mathrm{kg}$ IV, fall in SBP was below baseline but it was not significant $(\mathrm{p}>0.05)$ and with 3 microgram $/ \mathrm{kg}$ fentanyl IV, fall in SBP at $2 \mathrm{~min}, 5 \mathrm{~min}$ was significantly more $(p<0.05)$ compared to group I.

After laryngoscopy and intubation, in control group there was a classical pressor response and mean SBP showed maximum increase to $157.6 \pm 8.2110$, a rise by $42(36.33 \%)$ at $1 \mathrm{~min}$. At $5 \mathrm{~min}$ of post intubation there was significant fall in SBP by $4.87(4.21 \%)$. These findings were similar to the study done by P Agarwal et $\mathrm{al}^{20}$

Chung and Evans, ${ }^{10}$ study showed that, increase in SBP was significantly less in fentanyl group at $1 \mathrm{~min}$ post intubation. Infentanyl groups, SBP was lower than baseline value at $5 \mathrm{~min}$ post intubation. In our study also, 3 microgram $/ \mathrm{kg}$ IV fentanyl causes increase in SBP above baseline but it is significantly smaller $(\mathrm{p}<0.01)$ compared to control group during scopy, 30 sec, 1 min. post intubation. Similar results were observed with 2 microgram $/ \mathrm{kg}$ IV. In both the fentanyl groups, there was fall in SBP below baseline at $5 \mathrm{~min}$ and at 2 min, 5 minrespectively. Fall was significant with group III and it was insignificant with group II.

William M. Splinter et $\mathrm{al}^{21}$ used fentanyl in two different dose ie 1.5 microgram $/ \mathrm{kg}$ and 3 microgram $/ \mathrm{kg}$ in geriatric patients, above64 years. It was showed that fentanyl in both doses reduced the rise in SBP significantly $(\mathrm{p}<0.05)$. Our results of present study are comparable with the results obtained by William et al.

V. Abraham and B. Kaur ${ }^{17}$ study found that, study group showed only mild change in mean SBP from baseline. All these changes were statistically significant. It was concluded that with 3 microgram $/ \mathrm{kg}$ IV fentanyl, significant attenuation of cardiovascular response to intubation was achieved. In our study also, in group II and III there was mild change in SBP from baseline but when both were compared to control group the rise was significantly $(p<0.001)$ smaller in group II and III. Rise in mean SBP during intubation and fall at 2 min were statistically significant $(\mathrm{p}<0.01)$ while rise in SBP at 1 min was insignificant ( $p>0.05$ ).

Diastolic blood pressure: U.M. Kautto ${ }^{9}$ study showed that DBP did not increase significantly after intubation in F6 Group, whereas the increase in control and F2 group was significant $(p<0.001)$ compared to baseline value. It was concluded that 6 microgram $/ \mathrm{kg}$ fentanyl prevented the Arterial pressure increase during scopy and intubation and even a small dose of fentanyl 2 microgram $/ \mathrm{kg}$, significantly attenuated this response. In our study, in group II increase in DBP above baseline during scopy, $30 \mathrm{sec}, 1 \mathrm{~min}, 2 \mathrm{~min}$ post intubation were significantly less $(\mathrm{p}<0.001)$ than group I.

Chung and Evans ${ }^{10}$ studied showed that increase in DBP was significantly smaller in the fentanyl group at 1 min post intubation. It was demonstrated that 3 microgram $/ \mathrm{kg}$ IV fentanyl significantly attenuate the cardiovascular stress response to intubation. In our study, increase in DBP in group II and group III were significantly smaller $(\mathrm{p}<0.001)$ at $1 \mathrm{~min}$ post intubation. DBP increased by $39.87 \mathrm{~mm}$ of $\mathrm{Hg}$ increase in control group compared to $21.6 \mathrm{~mm}$ of $\mathrm{Hg}$ increase in group II and $1.94 \mathrm{~mm}$ of $\mathrm{Hg}$ increase in group III.

Willam $M$ Splinter et $\mathrm{al}^{21}$ study showed that fentanyl in both doses reduced the rise in DBP significantly $(\mathrm{p}<0.05)$. It was concluded that low dose fentanyl attenuated the haemodynamic response to laryngoscopy and intubation. In our study both fentanyl groups II and III showed increase in DBP above baseline which was significantly less $(p<0.001)$ than group I.

V. Abraham and B. Kaur $^{17}$ studied effect of3 microgram $/ \mathrm{kg}$ IV fentanyl, used adjunct to thiopentone sodium, and found that the control group and the study group showed very little change in mean DBP from baseline value. This was not significant when compared between the groups during study period. Change in DBP in study group, were not significant $(p>0.05)$ statistically. In our study, in group III, changes in DBP from baseline were, during scopy - decrease by $0.13(17 \%)$, at $1 \mathrm{~min}$ - increase by $1.94(2.6 \%)$, At 2 $\min$ - decreased by $0.06(0.08 \%)$. These changes were not significant $(\mathrm{p}>0.05)$ statistically.

Mean arterial pressure: One result of present study is comparable to the results obtained by William M. Spl interet al. ${ }^{21}$ In our study both the doses, 2 microgram $/ \mathrm{kg}$ and 3 microgram $/ \mathrm{kg}$ IV fentanyl, caused rise in MAP which was significantly smaller $(\mathrm{p}<0.001)$ as compared to group I or control group. At 2 min post intubation, group III causes significant fall in MAP below the baseline. In another study conducted by Channaiah VB et al., ${ }^{11}$ found that, for all recorded time duration, intergroup MAP yielded significant attenuation in the Fentanyl group.

Rate pressure product: Chung and Evans ${ }^{10}$ studied 28 patients aged between 65-84 years, were randomly assigned to either a control group (12) or treatment group (16) induced with 3 microgram $/ \mathrm{kg}$ fentanyl IV followed by thiopentone. It was showed that increase in rate pressure product were significantly smaller in the 
fentanyl group at $1 \mathrm{~min}$ post intubation. Increase was 24 times greater in control group. Rate pressure product increased by $72.2 \%$ in control group and by $36 \%$ in treatment group. It was concluded that 3 microgram $/ \mathrm{kg}$ fentanyl caused significant attenuation of cardiovasculare stress response to intubation.

Our results of present study are comparable with the results obtained by Chung and Evans. In our study, fentanyl in both doses showed rise in rate pressure product during scopy, $30 \mathrm{sec}, 1 \mathrm{~min}$, and $2 \mathrm{~min}$. But it was significantly smaller than in control group. In our study rate pressure product increased by 82.33 .06 $(89.74 \%)$ in control group and in group III increase was by $2909.73(31.8 \%)$.

\section{Conclusion}

From the present study, use of intravenous fentanyl in both doses, i.e. $2 \mathrm{mcg} / \mathrm{kg}$ as well as $3 \mathrm{mcg} / \mathrm{kg}$ is safe and effective for attenuation of hemodynamic response to laryngoscopy and intubation. At $30 \mathrm{sec}$ of intubation with fentanyl $2 \mathrm{mg} / \mathrm{kg}$, the change in pulse rate was insignificant compared to control group. But with 3 $\mathrm{mg} / \mathrm{kg}$ of fentanyl, the attenuation was significant at all the instances. Further, intravenous fentanyl citrate even in low dose of 2 microgram $/ \mathrm{Kg}$ body weight provide a simple, safe and effective method whereas intravenous fentanyl 3 microgram $/ \mathrm{Kg}$ body weight provides excellent attenuation of the hemodynamic response to laryngoscopy and intubation.

\section{References}

1. King BD, Harris LC, Griefenstein FE "Reflex circulatory responses to direct laryngoscopy and tracheal intubation performed during general anesthesia", Anaesthesiology 1951;12:556-566.

2. Figueredo E and Garciafuentes E. M. "Assessment of the efficacy of esmololon the hemodynamic changes induced by laryngoscopy and tracheal intubation: A metaanalysis", Acta Anaesthesiology Scand. 2001;1:1011-22

3. Fassoulaki a, Melemeni a, paraskeva a, Petropoulos G "Gabapentine attenuates the pressor response to direct laryngoscopy and tracheal intubation", Br. J. Anaesthesiology 2006;96:769-73

4. Hamill JF, Bedford RF, Weaver DC, Colohan AR "Lidocaine before endotracheal intubation: intravenous or laryngotracheal?”,Anesthesiology1981;55:578-81

5. Laurito CE, Baughman VL, Becker GL"Effects of aerosolized and/or intravenous lidocaine on hemodynamic responses to laryngoscopy and intubation in outpatients", Anesth. Analg. 1988: 389-92

6. Panda NB, BhartiN,Prasad S. "Minimal effective dose of magnesium sulfate for attenuationof intubation response in hypertensive patients", J. ClinAnesth Elsevier 2013; 25: $92-7$

7. F Menda, O Koner. "Dexmedetomidine as an adjunct to anesthetic induction to attenuate hemodynamic response to endotracheal intubation in patients undergoing fasttrack CABG", Annals of cardiac.2010;13:16-21.

8. Majumdar S. Comparative evaluation of oral clonidine and midazolam as premedication on preoperative sedation and laryngoscopic stress response attenuation for the patients undergoing general anaesthesia. Int. J. Med. Public Heal. 2013;3: 200-7
9. Kautto U.M, “ Topical nitroglycerine - A safeguard against pressure to tracheal intubation", Anaesthesia 1992;41:1087-97

10. Chung \& Evans, "Low dose fentanyl: haematodynamic response during induction and intubation in geriatric patients", Can. Anaesth . Soc. 1985;32:622-28.

11. Channaiah VB, Chary K, Vik JL, et al., "Clinical research: Low dose fentanyl: Hemodynamic response to endotracheal intubation in normotensive patients", Arch Med Sci 2008; 4: 293-99.

12. Feng CK, Chan KH, Liu KN, OrchLeety. A comparison of lidocaine, fentanyl and esmolol for attenuation of cardiovascular response to laryngoscopy and tracheal intubation. Acta Anaesthesiology, Sin 1996; 34:61-7

13. Martin et al.Low dose fentanyl blunts circulatory response to tracheal intubation.

14. Anaesthesia and analgesia 1982;61:680-84

15. Miller DR, Martineau RJ. Effect of Alfentanil on the hemodynamic and catecholamine response to tracheal intubation. Anaesth. Analg. $1993: 1040-6$

16. Korpinen R, Saarnivaara L, Siren K. Modification of hemodynamic responses to induction of anaesthesia and tracheal intubation with alfentanil, esmolol and their combination. Can. J. Anaesth. 1995; 42; 298-304

17. Kirby IJ, Northwood D. Modification by alfentanil of the hemodynamic response to tracheal intubation in elderly patients. A dose response study. Br. J. Anaesth. 1988: 384-7

18. V. Abraham, B Kaur, "Low dose of fentanyl blunts circulatory response to tracheal intubation in normotensive patients", Indian J Anaesth 2001;45:287

19. Savio KH, Tait G, Karkouti K, et.al, "The safety of perioperative esmolol: a systematic review and meta-analysis of randomized controlled trials", AnesthAnalg 2011;112:267-81.

20. Valiallah Hassani, Gholamreza Movassaghiet. al., "Comparison of Fentanyl and Fentanyl Plus Lidocaine on Attenuation of Hemodynamic Responses to Tracheal Intubation in Controlled Hypertensive Patients Undergoing General Anesthesia", Anesth Pain. 2013;2:115-8.

21. P. Agrawal, S. Bhalla, I. Singh, "To study the efficacy of intravenous esmolol, lidocaine and diltiazem in attenuating hemodynamic response to laryngoscopy and intubation", Intern J Anesthesiol, 2010;28.

22. William M. Splinter et al, "Haemodynamic responses to larygoscopy band treacheal intubation in geriatric patients: Effects of fentanyl, lidocaine, thiopentone", Can .J. Anaesth. 1989;36:70-6. 